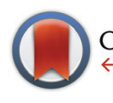

CrossMark \&lick for updates

Cite this: Polym. Chem., 2015, 6 , 8176

Received 11th August 2015,

Accepted 17th September 2015

DOI: $10.1039 / \mathrm{c} 5$ py01274k

www.rsc.org/polymers

\section{Wafer-scale synthesis of defined polymer brushes under ambient conditions $\uparrow$}

\author{
Tao Zhang, ${ }^{a}$ Yunhao Du, ${ }^{a}$ Jana Kalbacova, ${ }^{\mathrm{b}}$ René Schubel, ${ }^{a}$ Raul D. Rodriguez, \\ Tao Chen, ${ }^{c}$ Dietrich R. T. Zahn ${ }^{\mathrm{b}}$ and Rainer Jordan*a
}

\section{Introduction}

Since the first theoretical description of polymer brushes, ${ }^{1}$ their synthetic realization, mainly by surface-initiated polymerization techniques (SIP) using a self-assembled monolayer (SAM) of the initiator, ${ }^{2}$ developed fast because of their potential as highly defined functional and adaptive coatings for all branches of technology and science involving an interface. ${ }^{3-5}$ However, the demanding and tedious preparation of endtethered, strictly linear, narrow dispersed and dense polymer brushes on substrates still limits their broader application. ${ }^{6,7}$ Especially the preparation of homogeneous brush coatings on planar substrates is limited to areas of typically one or few square centimeters as the planar substrates have to be completely submerged in a substantial volume of the reaction solution in a rather big reaction vial. This is cost intensive, inefficient and renders the preparation of defined brushes by

\footnotetext{
${ }^{a}$ Professur für Makromolekulare Chemie, Technische Universität Dresden, Mommsenstr. 4, 01062 Dresden, Germany.E-mail: rainer.jordan@tu-dresden.de ${ }^{b}$ Semiconductor Physics, Technische Universität Chemnitz, 09107 Chemnitz, Germany

${ }^{c}$ Department of Polymer and Composite, Ningbo Institute of Materials Technology and Engineering, Chinese Academy of Sciences, 519 Zhuangshi Road, 315201 Ningbo, P.R. China

$\dagger$ Electronic supplementary information (ESI) available. See DOI: 10.1039/ c5py01274k
}

living ionic polymerizations (SI-LIP) difficult because of the strict reaction conditions. ${ }^{8,9}$ Alternatively, surface-initiated free radical polymerizations (SI-FRP) can be used but at the cost of the structural definition of polymer grafts due to chain transfer and termination. The compromise between both is offered by surface-initiated controlled radical polymerizations (SI-CRP) and especially surface-initiated atom transfer radical polymerization (SI-ATRP). ${ }^{10}$ However, SI-ATRP requires substantial amounts of chemicals, especially metal catalysts and the reaction mixtures must be rigorously deoxygenated. ${ }^{10,11}$ Hence, only few reports on the large-scale synthesis of polymer brushes by SI-ATRP can be found. ${ }^{12,13}$ Lately, several strategies have been developed to minimize the metal (i.e. copper) consumption by constant regeneration of the activator $(\mathrm{Cu}(\mathrm{I})$ species) from the $\mathrm{Cu}(\mathrm{II})$ deactivator by in situ reduction by chemical, ${ }^{12,14}$ electro- ${ }^{15}$ or photochemical means ${ }^{16}$ or with a sacrificial anode. ${ }^{17}$ The activator regeneration renders the SIP oxygen tolerant as first demonstrated by Matyjaszewski et al. ${ }^{12}$ Using a air tight jar, homo- and diblock copolymer brushes were prepared with a grafting density of 0.4 chains per $\mathrm{nm}^{2}$. Recently, Dunderdale et al. ${ }^{14}$ developed the "paint-on"-ATRP to create very thick poly(2-(dimethylamino)ethyl methacrylate) (PDMEMA) polymer brushes over very large areas and under ambient conditions with ascorbic acid as the reducing agent. This intriguing approach does not require a dedicated reaction vial. Unfortunately, this method is until now limited to the 
polymerization of DMAEMA. In a follow-up paper the same group reported on the preparation of hydrophobic polymer brushes by oxygen-tolerant SI-ARGET-ATRP at room temperature. ${ }^{18}$ However, the substrates are again submerged in the reaction solution. A more versatile and much faster SIP-CRP namely, the surface-initiated $\mathrm{Cu}(0)$-mediated controlled radical polymerization (SI-CuCRP) was very recently reported by us. ${ }^{19}$ The SI-CuCRP is performed without the addition of copper salts or reducing agents and only with a solvent, a ligand, a monomer and a copper plate as the metal source is needed. The plate simultaneously acts as a lid and confines the reaction space to a minimal volume of some $\mu \mathrm{L}$. The SI-CuCRP proceeds significantly faster than any other SI-CRP at room temperature, ${ }^{17,19-21}$ is applicable to a broad variety of monomers, is strictly surface-confined and yields dense ( 0.8 chains per $\mathrm{nm}^{2}$ ) and narrow dispersed polymer brushes. Since, SI-CuCRP is performed with only minimal volumes of reaction solution that fills the narrow gap between the substrate and the copper plate, this technique has the potential to be scaled up to the preparation of polymer brush coatings covering entire wafers.

Herein we report on the facile preparation of densely grafted, narrow dispersed homo- as well as multiblock copolymer brushes on the wafer scale at room temperature and in air. Moreover, a simple new lithographic technique is presented to prepare structured polymer brush layers by copper plate proximity printing $\left(\mathrm{CP}^{3}\right)$.

\section{Results and discussion}

\section{Oxygen tolerance of SI-CuCRP}

We first tested the oxygen tolerance of SI-CuCRP with various monomers. As sketched in Fig. 1a, a silicon wafer piece (with $\left.300 \mathrm{~nm} \mathrm{SiO}_{2} ; c a .0 .7 \times 1.5 \mathrm{~cm}\right)$ modified with a SAM of a stan- dard ATRP initiator (surface-bound 2-bromoisobutyryl bromide, APTES-BiBB) was covered by a copper plate leaving a gap of $D=0.5 \mathrm{~mm}$ with the aid of two spacers and then fixed by a clamp. The gap was filled with a solution of the respective monomer and ligand (1,1,4,7,7-pentamethyldiethylenetriamine, PMDETA) in methanol/water $(1: 2, \mathrm{v} / \mathrm{v})$ using a pipette. Neither the solvent nor the monomers were de-oxygenated and the entire assembling was performed in air. The assembly was left for $1 \mathrm{~h}$ at room temperature in air before the plates were separated, the substrate thoroughly cleaned and analyzed. Under ambient conditions, the SI-CuCRP converted all tested monomers to polymer brushes of remarkable optical thicknesses, $d$, as determined by ellipsometry. Inspection of the brushes by AFM revealed smooth and defect free surfaces with similar brush heights $(h)$. Even from methyl methacrylate (MMA) a polymer brush with a collapsed brush height of $h=$ $110 \mathrm{~nm}$ was formed although the solubility of the monomer in water/methanol is low (Fig. 1b, Table 1). Wetting experiments of the various brushes revealed typical water contact angles that were found to be constant throughout the surfaces (Fig. 1b insets). Apparently, the SI-CuCRP is highly oxygen tolerant. We explain this by the confinement of the reaction solution between the two facing plates as well as by a constant savaging of oxygen by $\mathrm{Cu}(0 / \mathrm{r})$ oxidation with an infinite $\mathrm{Cu}(0)$ reservoir provided by the bulk copper plate. Interestingly, in the presence of oxygen, thicker brushes were obtained as compared to SI-CuCRP under inert conditions and significantly thicker than other recently developed SI-CRP methods (Table 1). ${ }^{19}$

\section{Preparation of polymer brushes on the wafer-scale}

Because of the oxygen tolerance of the SI-CuCRP and the simple setup that do not require a reaction vial, the method is easily scalable to entire wafers with minimal amounts of chemicals. Fig. 2 outlines the facile fabrication of a polymer
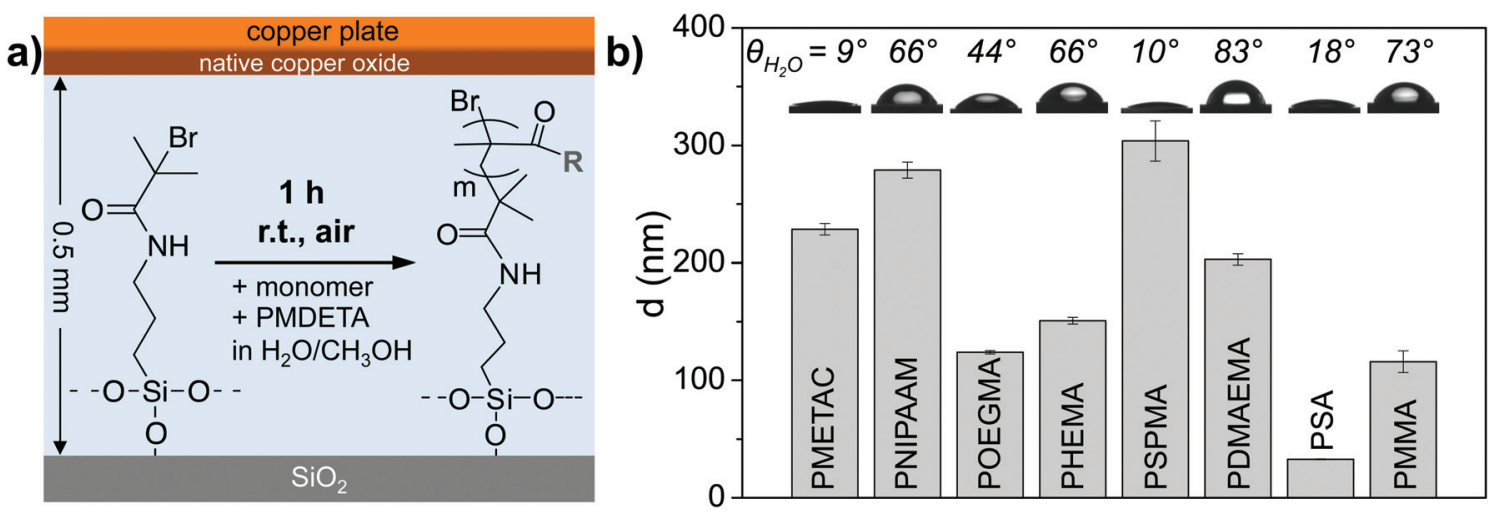

Fig. 1 (a) Reaction scheme for the surface-initiated $\mathrm{Cu}(0)$-mediated controlled radical polymerization (SI-CuCRP) using a surface modified silicon wafer piece bearing a standard initiator (APTES-BiBB) a facing copper plate at a distance of $0.5 \mathrm{~mm}$ and a solution of the monomer, the ligand (PMDETA) in water/methanol. (b) Polymer brush layer thickness, $d$, as determined by ellipsometry and water contact angles for the polymer brushes after SI-CUCRP for $1 \mathrm{~h}$ at ambient conditions (room temperature, handling in air). Monomers: (methacryloyloxy)ethyl trimethylammonium chloride (METAC), $\mathrm{N}$-isopropylacrylamide (NIPAAM), oligo(ethylene glycol) methyl ether methacrylate (OEGMA 475$)$, 2-hydroxyethyl methacrylate (HEMA), 3-sulfopropyl methacrylate potassium salt (SPMA), 2-(dimethylamino)ethyl methacrylate (DMAEMA), sodium acrylate (SA), Methyl methacrylate (MMA). The high $\theta_{\text {water }}$ for PDMAEMA indicates a (partial) transesterification of PDMAEMA to PMMA during the polymerization in water/methanol. ${ }^{22}$ 
Table 1 Polymer brush growth rate $(\delta d)$ obtained by SI-CuCRP under ambient and inert conditions in comparison to surface-initiated photoATRP (SI-photoATRP) and surface-initiated sacrificial anode ATRP (SI-saATRP)

\begin{tabular}{lcccc}
\hline & \multicolumn{2}{l}{ SI-CuCRP $^{19}\left(\mathrm{~nm} \mathrm{~h}^{-1}\right)$} & & \\
\cline { 2 - 3 } Monomer & In air & $\mathrm{O}_{2}$ free & $\begin{array}{l}\text { SI-photoATRP } \\
\left(\mathrm{nm} \mathrm{h}^{-1}\right)\end{array}$ & $\begin{array}{l}\text { SI-sa-ATRP }^{17} \\
\left(\mathrm{~nm} \mathrm{~h}^{-1}\right)\end{array}$ \\
\hline METAC & 228 & 180 & - & 30 \\
SA & 33 & - & - & 77 \\
OEGMA & 124 & 106 & 23 & 100 \\
NIPAAM & 279 & 190 & 95 & 38 \\
DMAEMA & 203 & 200 & 60 & 121 \\
HEMA & 150 & 140 & - & \\
SPMA & 304 & 270 & 130 & $3^{c}$ (ref. 20) \\
MMA & $115^{a}$ & $80^{b}$ & &
\end{tabular}

${ }^{a}$ The monomer solution showed two layers due to the poor dissolution of MMA in methanol/water mixture, both of the two layers used for SI-CuCRP but only from the lower aqueous layer brush formation was obtained. ${ }^{b} 0.5 \mathrm{~mL}$ DMSO used as solvent instead of methanol/water, the other parameters were identical. ${ }^{c}$ Irradiation from a household fluorescent lamp in the spectral range of 400-750 nm. brush coating on the wafer-scale. The entire procedure was performed on a lab bench under ambient conditions.

Following the same procedure as described above for small wafer pieces, an entire 4-inch wafer was coated by SI-CuCRP with a PMETAC brush (Fig. $2 \mathrm{a}$ and b, movie 1 and 2 in ESI $\dagger$ ) using only $4 \mathrm{~mL}$ of the reaction solution. X-ray photoelectron spectroscopy (XPS) unambiguously confirmed the identity of the PMETAC layer (Fig. S3†). Optical inspection of the wafer revealed only partial inhomogeneities and a thin, approx. $5 \mathrm{~mm}$ wide rim at the wafer edge. The rim is presumably caused by the constant diffusion of air into the solution and/ or by solution evaporation. The thicker brush areas are most probable caused by a slightly different distance between the copper plate and the substrate. Hence, this area is covered by a thicker brush of $\approx 320-355 \mathrm{~nm}$. Otherwise ellipsometry mapping of the entire wafer revealed a uniform PMETAC brush of $d=253 \mathrm{~nm}$ and a variation below $25 \mathrm{~nm}(10 \%)$ throughout the entire wafer surface area of $81 \mathrm{~cm}^{2}$ (Fig. 2d and e). Additionally, the supernatant solution was collected after the reaction and analyzed. In agreement with previous results with smaller substrates, ${ }^{19}$ no free polymer could be isolated by
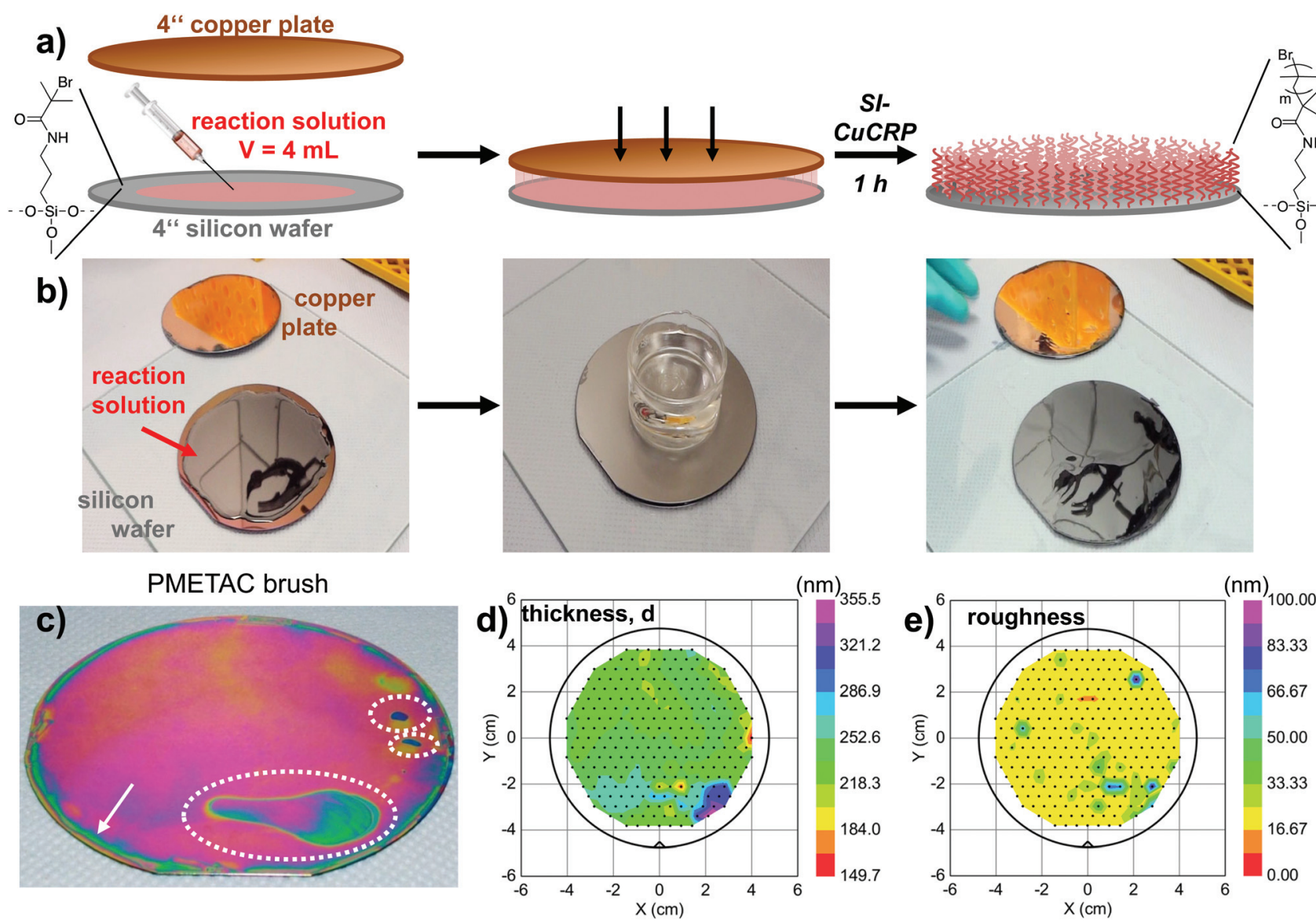

Fig. 2 Stepwise fabrication of PMETAC brush on 4-inch wafer. (a) Schematic illustration for the processes. (b) Digital stills from movie 1 in the ESI $\dagger$ illustrating the simple steps for fabrication of a wafer-scale PMETAC brush. The water filled jar is used to apply slight pressure. (c) Photograph of the dry PMETAC polymer brush covering the entire wafer. Interference colors indicate brush thickness variations caused by incomplete wetting of the wafer by the reaction solution (dashed lines) and a thin rim of lower brush thickness (arrow). Ellipsometry surface mapping of (d) the optical thickness, $d$, and (e) the roughness of the PMETAC brush throughout the wafer (272 individual measurements at locations indicated by black dots). 
precipitation or detected by GPC of the crude solution. We conclude that the SI-CuCRP is strictly surface confined and yields only surface-grafted polymers.

As a second example, a 4-inch wafer was modified with a PNIPAAM brush by SI-CuCRP as described above (Fig. 3). Again, optical inspection of the dry wafer revealed a uniform brush layer with minor thickness variations and a rim area as apparent by the interference color. A detailed AFM analysis at representative areas gave an $h=297 \mathrm{~nm}$ and a very low roughness below $1 \mathrm{~nm}$ (Fig. 3b). Ellipsometry mapping along 4 radial lines gave a $d=278 \mathrm{~nm}$ across the entire wafer (Fig. 3c). As already visible by the interference colors, again only one area had a higher $d \approx 350 \mathrm{~nm}$ (green line in Fig. 3c). Normally, the analysis of polymer brushes are restricted to surface analysis such as the brush thickness, swelling properties etc. Only, rarely the amount of grafted polymer is sufficient to analyze the polymer itself by common polymer analytical techniques such as gel permeation chromatography (GPC) or NMR spectroscopy. This wafer-scale synthesis of polymer brushes now gives access to these techniques by degrafting of the brush, collection of the polymer and full analysis of the polymer. We detached the PNIPAAM brush from the wafer, omitting the rim and the inhomogeneity (thicker brush region marked in blue, Fig. 3a), with $\mathrm{KOH}_{\mathrm{aq}}$ and analyzed the crude solution by GPC
(Fig. 3c). The GPC trace gave a monomodal and narrow elution peak for the detached PNIPAAM with a narrow dispersity of $D=1.10$ and a very high number average molar mass of $M_{\mathrm{n}}=$ $240 \mathrm{~kg} \mathrm{~mol}^{-1}$ which calculates to an average degree of polymerization of $P_{\mathrm{n}}=2120$. The very high molar mass obtained within $1 \mathrm{~h}$ reaction time at room temperature as well as the low dispersity of the degrafted polymer indicates that the SI-CuCRP is ultrafast and highly controlled under ambient conditions. The low dispersity of the degrafted polymer also corroborates the very low surface roughness of the brush layer found by AFM and the uniform $d$-values across the wafer. From $M_{\mathrm{n}}$ and the layer thickness, the grafting density, $\sigma$, can be calculated using the polymer brush scaling laws to be 0.94 chains per $\mathrm{nm}^{2}$ (Table S2 $\dagger$ ). ${ }^{1}$ This is one of the highest grafting densities reported to date for polymer brushes on solids. To outline the dramatic effect of this very high grafting density of such a long polymer on the chain stretching, one can compare the dimension of a random coil to the brush thickness. The radius of gyration of a PIPAAM chain with $P_{\mathrm{n}}=2120$ is only $R_{\mathrm{g}}=5.64 \mathrm{~nm}$ while the brush thickness was determined to be $h=297 \mathrm{~nm}$. For terminally grafted polymers, the ratio of $h / R_{g}$ is used to classify the layer into $h / R_{\mathrm{g}}<1$ as the mushroom regime and $>1$ being already a polymer brush. As apparent, the PNIPAAM as prepared by SI-CuCRP yields a ratio of
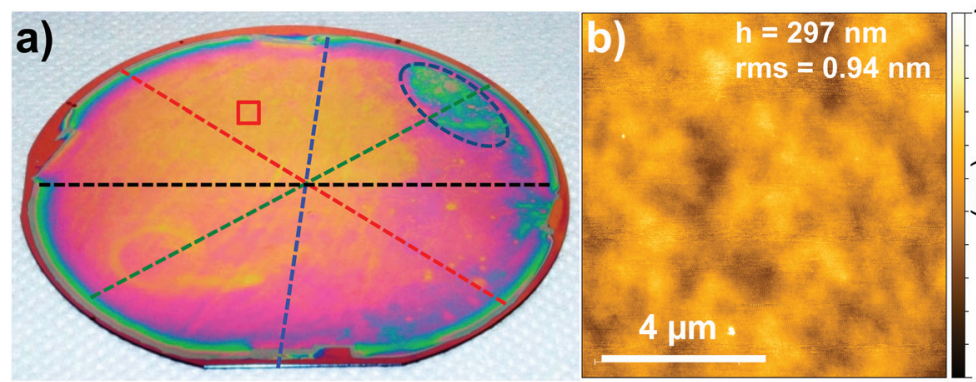

d) GPC of detached brush

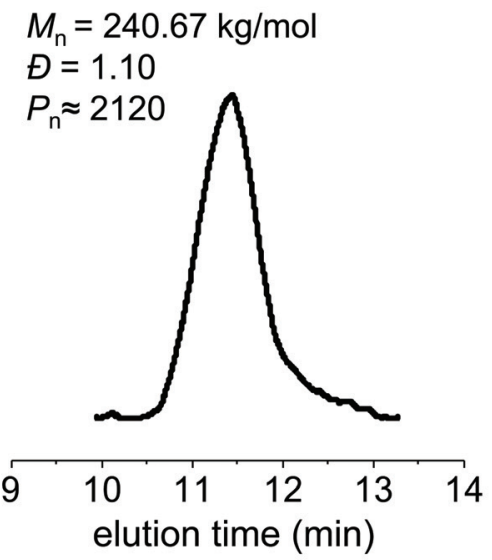

e)

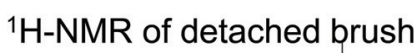

4.00
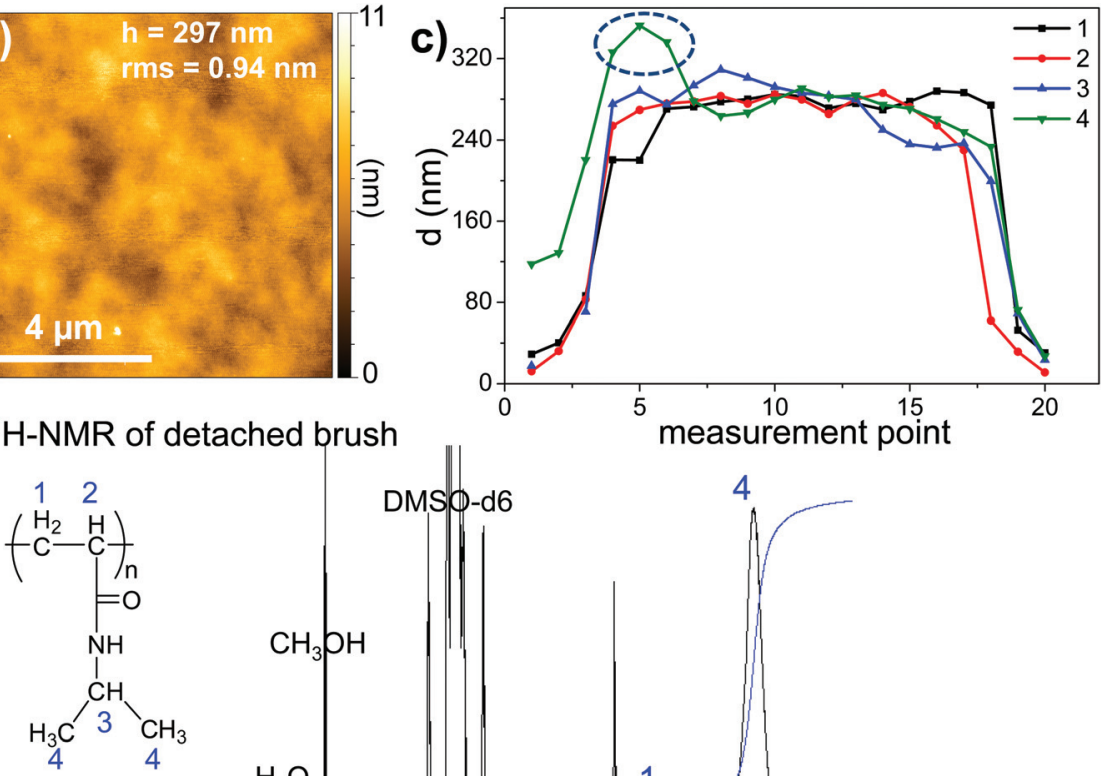
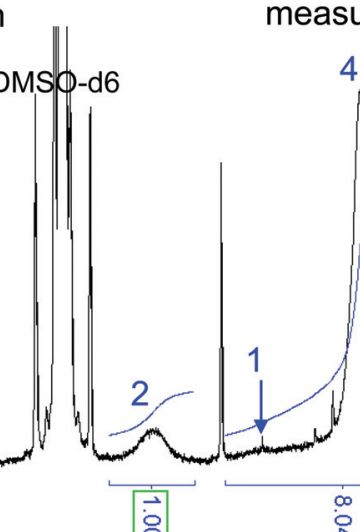

2.50
ppm

Fig. 3 PNIPAAM brush on a 4-inch wafer. (a) Photograph of the dry PNIPAAM brush covering the entire wafer. (b) Detailed AFM scan (10 $\left.\times 10 \mu m^{2}\right)$ at representative area indicated in (a) by red box. (c) Dry PNIPAAM brush optical thickness, $d$, measured by ellipsometry along radial lines indicated by colored dashed lines in (a) (20 measurements per line). (d) GPC trace of detached PNIPAAM brush. (e) ${ }^{1} \mathrm{H}-\mathrm{NMR}$ spectrum of the crude solution with the detached PNIPAM brush. All peaks are assignable to PNIPAAM and the signal integrals are as expected. The strong solvent signals are due to the etching process. 
$h / R_{\mathrm{g}}=52.66$ so, deep in the brush regime. In fact, the layer thickness of the dry collapsed brush is already approaching the dimension of a fully stretched polymer chain with a contour length of $L=636 \mathrm{~nm}$ at an $h / L=0.47$.

Finally, the amount of detached PNIPAAM in the crude solution is sufficient for ${ }^{1} \mathrm{H}-\mathrm{NMR}$ spectroscopy. The spectrum shown in Fig. 3e confirms unambiguously the chemical identity of PNIPAAM with all peaks assignable to the polymer and correct signal integrals. Most probably, this is the first ${ }^{1} \mathrm{H}-\mathrm{NMR}$ spectrum of a polymer grown by SIP from a flat surface. It is noteworthy that the fabrication of polymer brushes on the wafer scale is not only beneficial for advanced brush applications requiring large uniform surfaces and high-throughput experimentation but also allows for facile and detailed characterization of the brush by standard polymer analysis.

\section{Preparation of multiblock copolymer brushes}

Block copolymer brushes are highly adaptive surfaces that respond to environmental changes by immediate surface reconstruction. ${ }^{23,24}$ They allow for the combination of very different chemical and physical properties and are used to host, screen and stabilize nano-sized functional entities such as nanoparticles or proteins to be used as biosensors and as nanoactuators. ${ }^{25-28}$ There are numerous examples for the synthesis of diblock copolymer brushes mainly by SI-CRP techniques, but to the best of our knowledge neither triblock nor higher ordered multi-block brushes are reported until now. In solution, the $\mathrm{Cu}(0)$-mediated CRP is known for its high endgroup fidelity $^{29-31}$ and first synthesis of high-order multiblock copolymers has been recently demonstrated using a $\mathrm{Cu}$ wire. $^{32,33}$ Motivated by these studies, we aimed for the synthesis of the very first tetrablock copolymer brush. SI-CuCRP was performed alternatively with OEGMA $_{475}$ and HEMA on a large, half-wafer sized substrate (Fig. 4a). After the first SI-CUCRP for $30 \mathrm{~min}$ at r.t. in air the wafer was rigorously cleaned and AFM section analysis at an inflicted defect (Fig. 4c and $55 \dagger$ ) revealed the formation of a homogeneous POEGMA with $h=81 \mathrm{~nm}$ and a roughness of only $\mathrm{rms}=1.7 \mathrm{~nm}$ (deter-

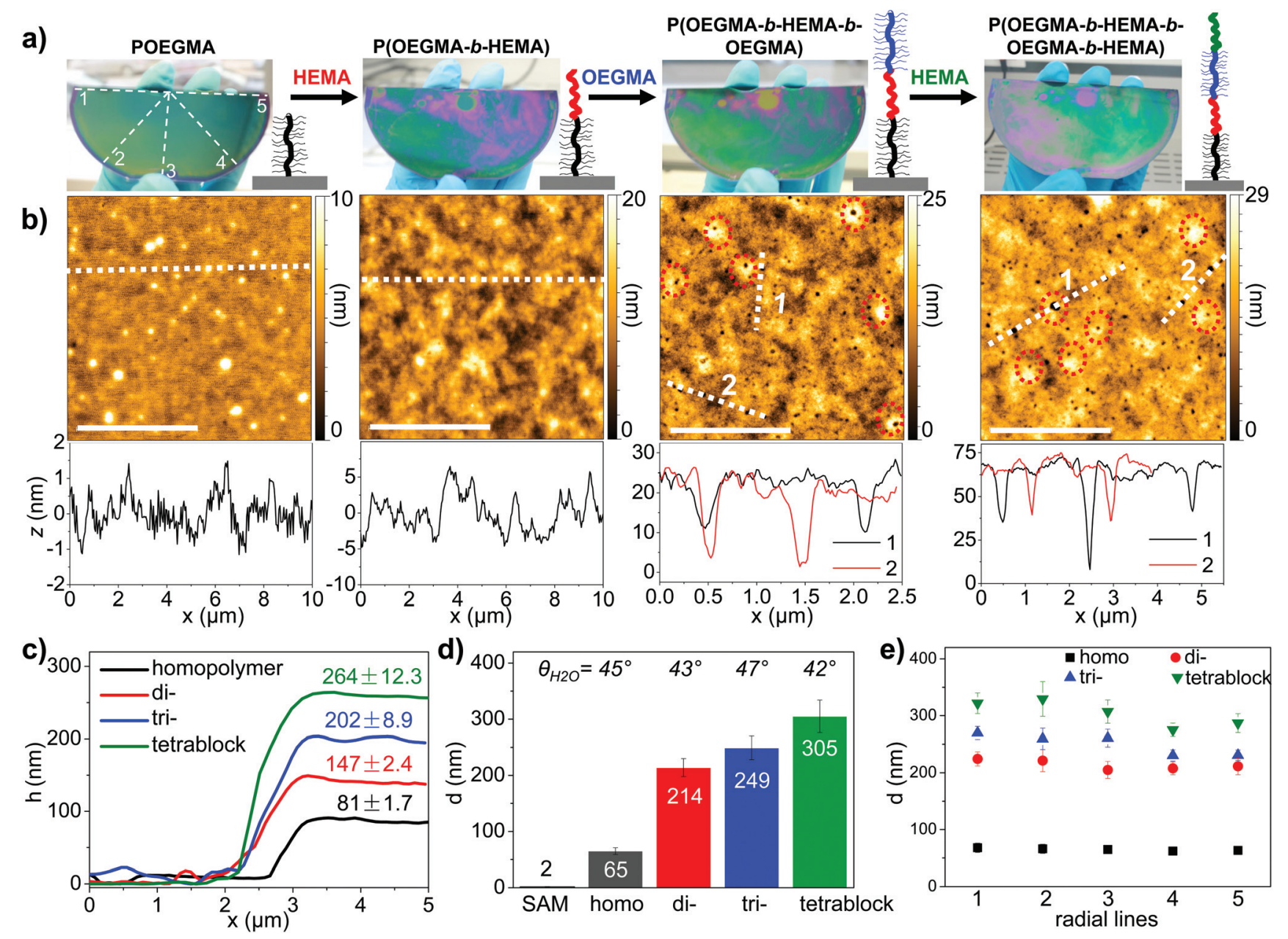

Fig. 4 Preparation of a P(OEGMA- $b$-HEMA-b-OEGMA- $b$-HEMA) tetrablock copolymer brush by SI-CuCRP on the wafer-scale under ambient conditions. (a) Photographs of the homo, di-, tri- and tetrablock copolymer brush. Each block was prepared by SI-CuCRP for 30 min. (b) AFM scans $\left(10 \times 10 \mathrm{\mu m}^{2}\right)$ and corresponding surface profiles of the respective of homo and block copolymer brushes shown a). (c) AFM section analysis of homo and block copolymer brushes shown in (a) at an inflicted defect. (d) The average optical thickness, $d$, along radial lines across the entire wafer. (e) Development of $d$ along the lines for homo and multiblock copolymer brushes. 
mined from the entire scan area shown in Fig. 4b). The same wafer was subjected to a second SI-CuCRP of HEMA giving a diblock copolymer with $h=147 \pm 2.4 \mathrm{~nm}$, thus adding $66 \mathrm{~nm}$ brush layer thickness. The third SI-CuCRP of OEGMA 475 adds another $55 \mathrm{~nm}$ to a triblock copolymer of $h=202 \pm 8.9 \mathrm{~nm}$ and finally, the forth SI-CuCRP of HEMA gave a P(OEGMA- $b$ HEMA- $b$-OEGMA- $b$-HEMA) tetrablock copolymer brush of a total $h=264 \pm 12.3 \mathrm{~nm}$. Please note that after each step, the substrate was thoroughly cleaned by ultrasonication for $5 \mathrm{~min}$ in water and drying by a jet of nitrogen and the substrate was always handled in air. Additional ellipsometry mapping of the wafers along radial lines confirmed the layer thickness development by each polymerization step (Fig. 4d) and the homogeneous layer thickness over the entire wafer (Fig. 4e). Furthermore, water contact angle measurements indicated the alternating change of the surface wetting behavior depending on the exposed polymer block with PHEMA being slightly more hydrophilic than POEGMA. Besides the expected brush thickness increase with each SI-CuCRP, a systematic increase of the layer roughness from $\mathrm{rms}=1.7$ to $12.3 \mathrm{~nm}$ is observable. Closer inspection by AFM revealed the appearance of randomly distributed dimples in the triblock brush layer around 10-20 nm deep, in the tetrablock up to $70 \mathrm{~nm}$ (Fig. 4b). Occasionally, higher rims surrounded the dimples. This feature has been observed before for densely grafted and thus strongly stretched polymer brushes prepared by living anionic polymerization that were alternatively exposed to good and bad solvent environments. ${ }^{8}$ The repeated swelling and collapsing of the brush pose a substantial stress on the brush assembly and eventually, the chains detach from the substrate to reduce the grafting density and chain stretching. The detached polymers are accumulating around the dimples into rims. This brush relaxation by chain scission has also been observed for densely grafted molecular brushes with long side chains upon additional stress caused by adsorption onto substrates ${ }^{34}$ and further examples were recently reviewed. ${ }^{35}$ This finding further corroborates the high grafting density of the brushes prepared by SI-CuCRP and underlines the substantial forces created by a high polymer grafting density. Please also note that this tetrablock brush consists of a linear PHEMA block alternating with a sterical demanding POEGMA bottle brush whose oligomeric side chains add substantially to the surface crowding.

This is the first reported example of the successful synthesis of a multiblock copolymer brush and demonstrates the high endgroup fidelity of SI-CuCRP. Moreover, the oxygentolerance and simple experimental setup of the polymerization readily allowed the preparation of homogeneous multiblock copolymer brushes on the wafer-scale under ambient con-

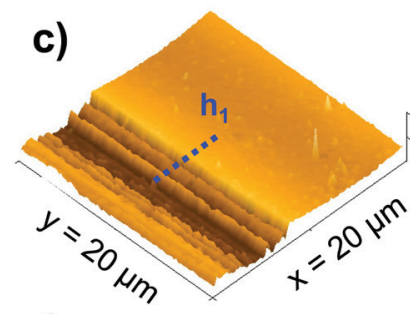

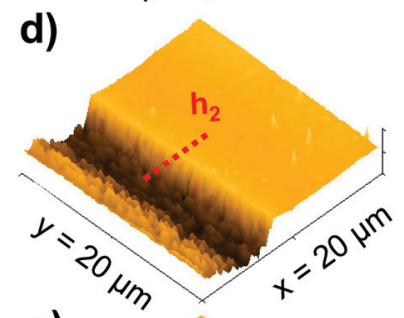
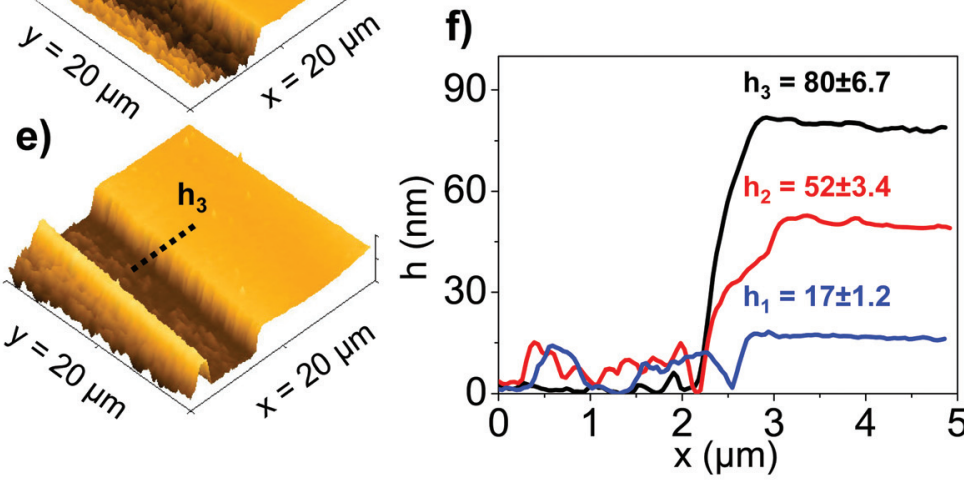

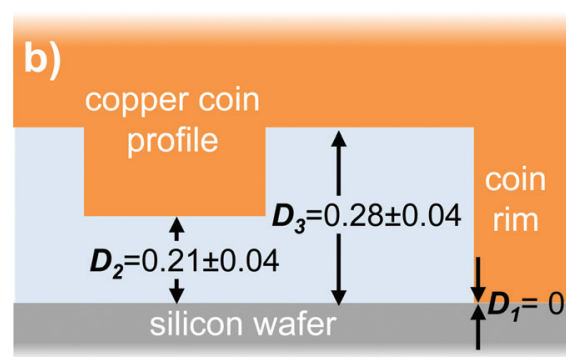

$L(\mathrm{~mm})$

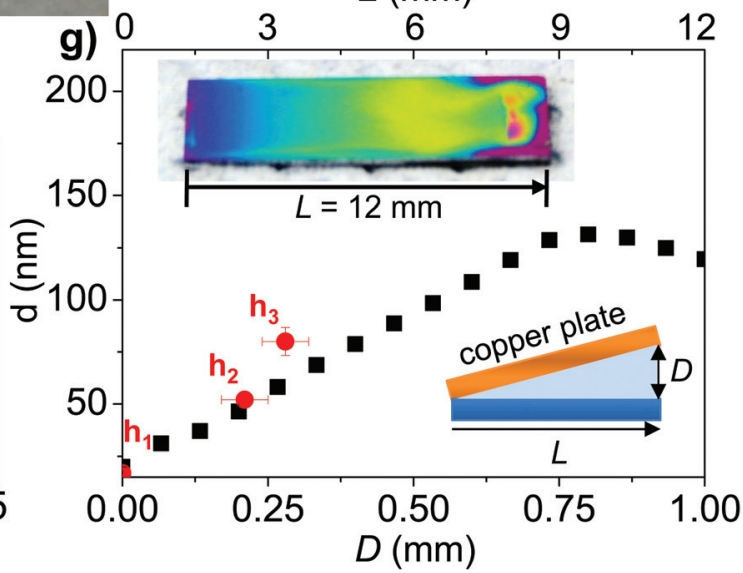

Fig. 5 Morphology control of polymer brushes by copper plate proximity printing $\left(C P^{3}\right)$. (a) Photograph of a 2 Euro cent coin (right) used as the $C P^{3}$ template and replication of the copper profile into a PMETAC brush. (b) Scheme of $\mathrm{CP}^{3}$ showing the coin profile with the distances in mm between the coin and the substrate at areas indicated in (a). The coin surface profile was determined by a vernier caliper and white light interferometry (Fig. S6†). (c)-(e) AFM scans of PMETAC brushes at areas indicated in (a). (f) Section analysis of (c)-(e). (g) Polymer brush height vs. distance for a PMETAC brush gradient prepared with a tilted copper plate along with the determined brush heights $\left(h_{1}-h_{3}\right)$ obtained by CP3. Inset: photo of the macroscopic PMETAC brush gradient prepared as the control. 
ditions. We do not see an inherent limit for the preparation of even higher ordered block copolymers other than C-C-bond chain scission with increasing length of the densely grafted polymer chains.

\section{Copper plate proximity printing $\left(\mathrm{CP}^{3}\right)$}

Previously, we reported a facile method to produce polymer brush gradients by SI-CuCRP by performing the polymerization with a tilted copper plate. ${ }^{19}$ The resulting brush layer thickness, $h$, was found to be a direct function of the distance, $D$, between the copper plate and the initiator bearing substrate. The $h-D$ correlation was found to be different for different monomers but linear over a wide range of e.g. $D=$ 0-0.75 mm for METAC. This unique behavior can also be used for a novel lithographic technique, the copper plate proximity printing $\left(\mathrm{CP}^{3}\right)$. For this a structured copper plate, such as a copper engraving plate or simply a copper coin is placed face down onto the initiator functionalized substrate and the gap filled with the reaction solution. The copper surface profile gives areas of different distances and thus the $\mathrm{CP}^{3}$ should result in a negative image of the copper profile by a morphologically controlled polymer brush.

To demonstrate the $\mathrm{CP}^{3}$ on a macroscopic scale, a 2 Euro cent coin was used to perform SI-CuCRP of METAC for $1 \mathrm{~h}$ under ambient conditions. As apparent from Fig. 5a, the coin profile was directly transferred into a structured PMEATC brush. The coin profile is characterized by three areas of relative heights giving three typical distances $\left(D_{1-3}=0,0.21\right.$ and $0.28 \mathrm{~mm}$, respectively) to the substrate when placed face-down (Fig. 5b). These gave three distinct brush heights of $h_{1}=17 \mathrm{~nm}$ (contact), $h_{2}=50 \mathrm{~nm}$ and $h_{3}=80 \mathrm{~nm}$ (Fig. 5c-f). The $h-D$ dependence the $\mathrm{CP}^{3}$ experiment correlates nicely with the results of the control experiment performed with a tilted copper plate (Fig. 5g). As seen in Fig. 5a, also smaller features (letters, stripes, stars and the structured globe) are clearly visible in the transferred image. The experiment shows that the $\mathrm{CP}^{3}$ is a very simple, development and resist-free method to prepare quite complex polymer brush structures on the micro- and macroscopic scale from easy to produce structured copper plates. In principle, the $\mathrm{CP}^{3}$ is scalable to any surface area and requires no complicated instrumentation. ${ }^{36}$

\section{Conclusions}

In summary, we demonstrated the oxygen-tolerance of SI-CuCRP by the fabrication of thick polymer brushes from a variety of monomers under ambient conditions. This allowed the modification of entire wafers by uniform polymer brush coatings using minimal amounts of chemicals. The brushes formed on large areas were degrafted and the substantial amounts of polymer obtained allowed a reliable characterization of the surface-grown polymer by common polymer analytical techniques such as GPC or NMR spectroscopy. This analysis revealed the formation of polymer brushes with very high molar mass and narrow dispersity that calculates to a grafting density close to 1 chain per $\mathrm{nm}^{2}$. Furthermore, the high endgroup fidelity of SI-CuCRP allowed for the preparation of a defined tetrablock copolymer brush, thus the first example of a higher order multiblock copolymer brush. Finally, we developed a facile lithographic technique, the copper plate proximity printing $\left(\mathrm{CP}^{3}\right)$, which transfers a copper plate surface profile directly into a polymer brush "image". ${ }^{36}$

The fast, facile, versatile and scalable SI-CuCRP do not require complex instrumentation or de-oxygenation of the chemicals and is thus most suitable for the large scale production of defined, densely grafted polymer brushes for surface engineering.

\section{Experimental section}

Details of the experimental procedures are given in the ESI. $\dagger$

\section{Acknowledgements}

T. Z. acknowledges the China Scholarship Council (CSC). R.J. and J.K. acknowledge the Cluster of Excellence "Center for Advancing Electronics Dresden” (cfaed). R.D.R. acknowledges DFG-Research Unit 1713 "Sensoric Micro- and Nanosystems". T.C. acknowledges Thousand Young Talents Program, Natural Science Foundation of China (51303195), and Excellent Youth Foundation of Zhejiang Province of China (LR14B040001). The authors thank Prof. Andrés Fabián Lasagni and Sophie Dani for white light interferometry measurement of the coin. The authors thank Dr. Ovidiu D. Gordan for help with the spectroscopic ellipsometry mapping.

\section{Notes and references}

1 S. T. Milner, Science, 1991, 251, 905-914.

2 Surface-Initiated Polymerization I (Advances in Polymer Science), ed. R. Jordan, Springer, 2006, vol. 197, pp. 214.

3 X. Du, L. X. Li, J. S. Li, C. W. Yang, N. Frenkel, A. Welle, S. Heissler, A. Nefedov, M. Grunze and P. A. Levkin, Adv. Mater., 2014, 26, 8029-8033.

4 X. Laloyaux, E. Fautre, T. Blin, V. Purohit, J. Leprince, T. Jouenne, A. M. Jonas and K. Glinel, Adv. Mater., 2010, 22, 5024-5028.

5 Y. Yu, C. Yan and Z. J. Zheng, Adv. Mater., 2014, 26, 55085516.

6 M. Krishnamoorthy, S. Hakobyan, M. Ramstedt and J. E. Gautrot, Chem. Rev., 2014, 114, 10976-11026.

7 T. L. Sun and G. Y. Qing, Adv. Mater., 2011, 23, H57-H77.

8 R. Jordan, A. Ulman, J. F. Kang, M. H. Rafailovich and J. Sokolov, J. Am. Chem. Soc., 1999, 121, 1016-1022.

9 R. Jordan and A. Ulman, J. Am. Chem. Soc., 1998, 120, 243247.

10 R. Barbey, L. Lavanant, D. Paripovic, N. Schuwer, C. Sugnaux, S. Tugulu and H. A. Klok, Chem. Rev., 2009, 109, 5437-5527. 
11 J. D. Jeyaprakash, S. Samuel, R. Dhamodharan and J. Ruhe, Macromol. Rapid Commun., 2002, 23, 277-281.

12 K. Matyjaszewski, H. C. Dong, W. Jakubowski, J. Pietrasik and A. Kusumo, Langmuir, 2007, 23, 4528-4531.

13 A. Hucknall, A. J. Simnick, R. T. Hill, A. Chilkoti, A. Garcia, M. S. Johannes, R. L. Clark, S. Zauscher and B. D. Ratner, Biointerphases, 2009, 4, Fa50-Fa57.

14 G. J. Dunderdale, C. Urata, D. F. Miranda and A. Hozumi, ACS Appl. Mater. Interfaces, 2014, 6, 11864-11868.

15 B. Li, B. Yu, W. T. S. Huck, W. M. Liu and F. Zhou, J. Am. Chem. Soc., 2013, 135, 1708-1710.

16 J. E. Poelma, B. P. Fors, G. F. Meyers, J. W. Kramer and C. J. Hawker, Angew. Chem., Int. Ed., 2013, 52, 68446848.

17 J. F. Yan, B. Li, B. Yu, W. T. S. Huck, W. M. Liu and F. Zhou, Angew. Chem., Int. Ed., 2013, 52, 9125-9129.

18 G. J. Dunderdale, M. W. England, C. Urata and A. Hozumi, ACS Appl. Mater. Interfaces, 2015, 7, 12220-12229.

19 T. Zhang, Y. H. Du, F. Müller, I. Amin and R. Jordan, Polym. Chem., 2015, 6, 2726-2733.

20 T. Zhang, T. Chen, I. Amin and R. Jordan, Polym. Chem., 2014, 5, 4790-4796.

21 J. F. Yan, B. Li, F. Zhou and W. M. Liu, ACS Macro Lett., 2013, 2, 592-596.

22 X. Bories-Azeau and S. P. Armes, Macromolecules, 2002, 35, 10241-10243.

23 R. Verduzco, X. Y. Li, S. L. Pesek and G. E. Stein, Chem. Soc. Rev., 2015, 44, 2405-2420.

24 M. A. C. Stuart, W. T. S. Huck, J. Genzer, M. Muller, C. Ober, M. Stamm, G. B. Sukhorukov, I. Szleifer,
V. V. Tsukruk, M. Urban, F. Winnik, S. Zauscher, I. Luzinov and S. Minko, Nat. Mater., 2010, 9, 101-113.

25 J. N. Kizhakkedathu, K. R. Kumar, D. Goodman and D. E. Brooks, Polymer, 2004, 45, 7471-7489.

26 T. Chen, D. P. Chang, J. M. Zhang, R. Jordan and S. Zauscher, Adv. Funct. Mater., 2012, 22, 429-434.

27 A. A. Reitinger, N. A. Hutter, A. Donner, M. Steenackers, O. A. Williams, M. Stutzmann, R. Jordan and J. A. Garrido, Adv. Funct. Mater., 2013, 23, 2979-2986.

28 S. Gupta, M. Agrawal, M. Conrad, N. A. Hutter, P. Olk, F. Simon, L. M. Eng, M. Stamm and R. Jordan, Adv. Funct. Mater., 2010, 20, 1756-1761.

29 N. H. Nguyen, B. M. Rosen, G. Lligadas and V. Percec, Macromolecules, 2009, 42, 2379-2386.

30 G. Lligadas, B. M. Rosen, M. J. Monteiro and V. Percec, Macromolecules, 2008, 41, 8360-8364.

31 A. Anastasaki, V. Nikolaou, G. Nurumbetov, P. Wilson, K. Kempe, J. F. Quinn, T. P. Davis, M. R. Whittaker and D. Haddleton, Chem. Rev., 2015, DOI: 10.1021/acs. chemrev.5b00191.

32 A. H. Soeriyadi, C. Boyer, F. Nystrom, P. B. Zetterlund and M. R. Whittaker, J. Am. Chem. Soc., 2011, 133, 11128-11131.

33 F. Alsubaie, A. Anastasaki, P. Wilson and D. M. Haddleton, Polym. Chem., 2015, 6, 406-417.

34 S. S. Sheiko, F. C. Sun, A. Randall, D. Shirvanyants, M. Rubinstein, H. Lee and K. Matyjaszewski, Nature, 2006, 440, 191-194.

35 H. A. Klok and J. Genzer, ACS Macro Lett., 2015, 4, 636-639. 36 X. C. Zhou, X. L. Wang, Y. D. Shen, Z. Xie and Z. J. Zheng, Angew. Chem., Int. Ed., 2011, 50, 6506-6510. 